\title{
Visualising the Intended Practical Doing: Future-Oriented Movements in Swedish Vocational School Workshop Settings
}

\author{
Stig-Börje Asplund*, Nina Kilbrink, Hamid Asghari \\ Karlstad University Department of Educational Studies, Universitetsgatan 2, \\ 65188 Karlstad, Sweden
}

Received: 25 September 2020, Accepted: 06 April 2021

\begin{abstract}
Context: This article focuses on teaching and learning processes in a vocational classroom in Swedish vocational education. There are few studies within the field of vocational education that have a focus on how vocational learning is done in interaction in the vocational classroom/workshop, and what vocational learning content is displayed in the interaction between teacher and student, and thus made possible to learn. This article aims to fill this gap by exploring the future-oriented movements that take shape when a vocational teacher and vocational students negotiate how a practical task could, and should, be handled and solved in vocational teaching situations in vocational plumbing school workshop settings. An increased understanding of these processes can help to improve the actual teaching of a specific subject content to support students in their vocational learning, aiming for learning a professional trade.
\end{abstract}

Methods: The data consist of video recorded lessons from the Sanitary, Heating and Property Maintenance Programme in Swedish upper secondary school. Through concrete empirical examples from video recorded lessons the article explores the interaction between teachers and students in vocational school workshop settings using CAVTA. CAVTA is based on Conversation Analysis (CA) and Variation Theory (VT) and is a theoretical and methodological framework that can be used together and integrated to reach understanding of both how- and what-aspects of the learning process in practice, when analysing teaching and interaction.

${ }^{\star}$ Corresponding author: stig-borje.asplund@kau.se 
Findings: Findings show how aspects concerning a specific vocational learning content that revolves around a vocational practical doing compete for the space with a vocational learning content of a more general nature. These general objects of learning are also related to work-specific vocational learning and knowledge in relation to the future profession, but on a more general level than the task specific vocational knowledge. Altogether, this illuminates how different layers of work-specific vocational learning are made visible in the interaction, and how they mutually contextualise each other in the here and now.

Conclusion: This article illustrates that the specific and the general vocational learning content can complement each other and open up for a more in-depth vocational learning. In conclusion, this article emphasises the importance for vocational teachers to develop teaching strategies to navigate between helping the students in their problem solving here and now, and contextualising the specific vocational learning content and making vocational learning relevant for future vocational occupation and working life.

Keywords: Vocational Learning, Vocational Teaching, Vocational Education and Training, VET, CAVTA, Interaction

\section{Introduction}

A central feature of vocational education is the interaction that takes place between teachers and students, which can contribute to the development of the specific vocational content of the education and the profession (Andersson, 2019). Despite the proven importance of this interaction for students' learning and the development of vocational education, there is still a lack of studies that focus on the interaction that takes place between teachers and students when students learn a specific content in vocational education (Asplund \& Kilbrink, 2020; Schaap et al., 2012). In an ongoing research project, we shed light on precisely these issues by studying what happens when a teacher and students interact about a specific learning content in vocational education. In our data we can see that when students and teachers negotiate how a practical task should be handled and solved in a vocational teaching situation, they do not only orient themselves towards the practical doing here and now, but a lot of attention is also directed towards what has already been done, and what is to be done next. A concept used in conversational analytical research to describe these movements in time and space is longitudinal orientation (Sahlström, 2011). According to Sahlström et al. (2010), orientations towards a longitudinally established content constitute one of the core aspects that enables a situation to be described as a learning situation, not only analytically, but also for the participants there and then. These longitudinal orientations towards a specific content are thus very common in the data we have collected on teachers' and students' interaction in vocational education, and thus constitute central elements in the vocational education we have studied. 
In this article, we will further analyse some of the sequences from our material, with the aim of increasing our knowledge and understanding of the future-oriented movements in the interplay between teacher, students and a vocational subject content.

\subsection{Research on Longitudinal Aspects in VET}

In previous research on learning in vocational education one research strand is related to how learning in vocational education can be relevant for a future working life. Within this research, it has been emphasised that vocational education is not only about learning to perform a profession in a purely practical way, but that there is also a vocational content that is linked to a future professional competence to adequately meet the market's demands (Andersson, 2019; Nore, 2015; Tuomi-Gröhn \& Engeström, 2003; Kilbrink \& Bjurulf, 2013; Nylund \& Virolainen, 2019). Furthermore, previous studies have highlighted different kinds of learning and knowledge within vocational education, where the specific vocational learning content is one part, and learning for life in general is another (Baartman \& de Bruijn, 2011; Illeris, 2009; Kilbrink et al., 2014; Lindberg, 2003). These general competences include skills like arriving on time, being a loyal employee who can work together with others, being able to reflect on how specific practices may be integrated into other contexts, and having knowledge of social order (Baartman et al., 2018; Eiríksdóttir \& Rosvall, 2019). However, few studies focus on how the learning processes in vocational education are set into play when teachers and students interact in relation to learning a specific vocational learning content (Asplund \& Kilbrink, 2020; Kilbrink et al., 2021; Schaap et al., 2012).

Many studies that examine vocational education and its practice tend to focus on general pedagogical issues such as how meaning is negotiated between teachers and students and what communicative strategies teachers and students use when interacting with each other in teaching situations (Khaled et al., 2016; Schaap et al., 2017; Öhman, 2018; Öhman \& Tanner, 2017). Chan (2017), for example, focuses on the role of imitation in learning occupational skills through the mutual relationships between learners and "model", and de Saint-Georges and Filliettaz (2008), when examining the interactions in which apprentices engage, show how individual learning in vocational education is also a collective process in that it takes place in interaction with others.

What these previous research studies have in common is that they show the complexity of the learning processes students are involved in when they interact with each other and/or their teachers in different teaching situations. What many of these studies also show, although the focus in each study may be on other aspects, are the movements in time and space that are initiated by teachers and students in the interaction. Kilbrink and Asplund (2018) for example, show how a VET teacher, when instructing a student in a plumbing workshop lesson, relates to what has been done previously in a teaching situation, as welding instructions are 
given, thus using this movement in time and space as a resource in the teaching situation (see also Jakonen, 2018) when instructing the student how to weld (eg. Sakai et al., 2014). Focusing on how knowledge transits between individuals across time and space, de Saint-Georges and Filliettaz (2008) emphasise the role of close guidance as the way to untie the knots in apprentices' vocational learning trajectories. In their study, de Saint-Georges and Filliettaz show how apprentices can take the role of "trajectory managers", re-figuring explanations given to them by their teacher in the past when helping their peers - here and now - conducting a task that their peers experience as difficult.

In another study, Filliettaz et al. (2015) examine the role and place of guidance and mentoring in vocational education. Conceptualising mentoring practices as interactional accomplishments, Filliettaz et al. demonstrate that guidance is a complex process and that it can be dynamically combined and evolve in time when mentors and students are doing guidance, thus highlighting the importance of interactional competences for workers when "doing guidance".

However, a large part of previous research on the interaction between teachers and students in vocational education has focused on workplace-based teaching and learning activities, and on the whole, there are few studies that direct a special interest towards the specific content to be taught and learned in vocational education. Besides the work of scholars such as Asplund and Kilbrink (Asplund \& Kilbrink, 2018, 2020; Kilbrink \& Asplund, 2018), Gåfvels (2016) and Öhman (2018) who highlight specific dimensions of vocational learning, emphasising how it is often taught in interaction between teacher and student, and including an aspect of handicraft as well as a concrete doing and practical experience, there are few studies within the field of vocational education that have a focus on how vocational learning is done in interaction in the vocational classroom/workshop, and what vocational learning content is displayed in the interaction between teacher and student, and thus made possible to learn.

Not least, there is a lack of research that explores the movements in time and space that are set into play when teachers and students interact about a specific learning content in vocational plumbing education. Hence, there is a need for studies that direct a special focus on what happens when these movements are initiated here and now in interaction and what learning content is made relevant in these situations. An increased understanding of these processes can help to improve the actual teaching of a specific subject content to support students in their vocational learning, aiming for learning a professional trade (Asplund \& Kilbrink, 2018, 2020; Lucas et al., 2012). Hence, the aim of this study is to increase this knowledge and understanding of the future-oriented movements in the interplay between teachers, students and a vocational subject content. We will study longitudinal orientations towards a specific content based on the following research questions: 1) How is a common understanding of what is to be done and learned in vocational plumbing education established in the interaction between a teacher and students? 2) What content is made relevant in these processes? 


\section{Theoretical and Methodological Approach}

In the article, we will use Conversational Analysis together with Variation Theory as a tool to analyse the interaction that takes place in the classrooms between teachers and students. When we combine these theories, we use the abbreviation CAVTA (Conversation Analysis and Variation Theory Approach). We have previously used these theories together in analyses of teaching and learning processes in schools (Asplund \& Kilbrink, 2018, 2020; Kilbrink \& Asplund, 2018, 2020).

\subsection{Conversation Analysis}

The starting point for combining Conversational Analysis with Variation Theory into CAVTA is the now established view in contemporary conversational analytical research that learning is something that is done in interaction between people, and between people and artifacts in their specific surrounding (Melander \& Sahlström, 2010; Sahlström, 2011). The approach intersects with the learning theories that describe learning as a change in participation (Lave, 1993; Säljö, 2005). The conversation analysis is thus interested in how people construct meaning and understanding in interaction with each other and artifacts in the surrounding context, and what communicative resources (both verbal and embodied) are used in the interaction (Drew \& Heritage, 2006; Goodwin, 2000, 2006; Schegloff, 2007).

A fundamental principle in the conversational analytical approach is participants' work to establish an understanding of each other's actions when they interact with each other. In concrete terms, this means that participants themselves, when participating in interaction, analyse each other's actions, there and then, and show their understanding of these actions turn by turn. The participants' work of demonstrating their mutual understanding of each other thus gives the conversation analyst the opportunity to anchor the analysis empirically - i.e. in the participants' demonstrated understanding of the interaction. This so-called emic perspective (Duranti, 1997) which is sought in both data collection and the analytic work means that the analysis only focuses on what the participants themselves orient to and which actions and activities the participants themselves construct and make relevant in the interaction here and now. Accordingly, as a conversation analyst you cannot make any claim to make any statements concerning what conversation participants think or what they understand, nor what they don't understand, because the core of the Conversation Analysis approach is precisely to study phenomena from an "inside perspective" (eg. Sahlström, 2011).

In this article, we focus on the encounter between teacher, student and a specific content to be learned, and it is in this meeting that these two perspectives - Conversational Analysis and Variation Theory - can be used together, simultaneously and integrated in CAVTA in our analysis of the interaction that will be studied. 


\subsection{Variation Theory}

In Variation Theory, the specific focus on the learning content is central. The learning content in focus in teaching is called the object of learning, and it can differ between what the teacher aimed for (intended object of learning), what was possible to learn in the teaching/learning situation (enacted object of learning) and what the students actually learned (lived object of learning) (Lo, 2012; Marton \& Tsui, 2004). In our study, we solely focus on what is made possible to learn in the enacted teaching/learning situation - hence, the enacted object of learning. Furthermore, the object of learning has a direct and an indirect aspect, related to how the learning content should be learned, i.e. what ability (indirect aspect) is related to the learning content (direct aspect). For example, the object of learning can be about understanding something (for example how you should weld) when someone else shows you, or about being able to perform something on your own (for example put a weld). In the example, welding is constant as the direct aspect, while the indirect aspects (understanding or performing) differ (Asplund \& Kilbrink, 2020; Kilbrink \& Asplund, 2020).

One important aspect of teaching, emphasised in Variation Theory, is to make critical aspects (things you need to discern in order to learn the object of learning, see Pang \& Ki, 2016) visible to the learners by using different patterns of variation (Lo, 2012; Marton \& Tsui, 2004; Marton, 2015). Contrasting, as a pattern of variation is related to comparing different values of critical aspects, or to see how something could be done or not (e.g. you can hold like this when welding, but not like this, see Kilbrink \& Asplund, 2020); and generalisation as a pattern of variation is about highlighting different kinds and aspects of a phenomenon (there are for example different kinds of triangles) or ways of doing things (e.g. you can hold like this, or like this when welding, see Kilbrink \& Asplund, 2020).

Hence, critical aspects can vary (dimensions of variation) and every value of the dimension of variation is a critical feature. If colour is a critical aspect, blue can be an example of a critical feature of the critical aspect. We have chosen to call what the teacher aims for ("the target values of critical aspects", Pang \& Ki, 2016, p. 324) in their teaching the targeted critical feature (Kilbrink \& Asplund, 2020). When several critical aspects are present and varied in the teaching situation at the same time, the pattern of variation is fusion. Lo and Chik (2016) elaborate the concept of fusion to concern internal and external horizons of fusion, where internal horizons of fusion concern how the critical aspects of the object of learning interrelate, while external horizons of fusion are about how the object of learning and its critical aspects relate to an external context (compare also Kilbrink \& Asplund, 2018 concerning a vocational example).

When combining Variation Theory with CA in CAVTA, we can analyse in great detail how the enacted object of learning and its critical aspects and features are made visible (or not) by the use of different patterns of variation in the interaction between the teacher and learner(s). 


\section{Data}

The data collection for this study consists of video recorded lessons from the Sanitary, Heating and Property Maintenance Programme, which is a technical vocational programme in Swedish upper secondary school. The programme aims to educate future plumbers, and we have recorded the teaching that was conducted in school workshop sessions at two different occasions in the same class for a total of 4 hours and 36 minutes. In this article, we have chosen two teaching situations from the programme where future-oriented movements are set into play when the teacher and students interact in relation to a vocational subject content.

In Sweden, the vocational teacher has the responsibility for creating conditions for vocational learning for groups of up to 30 students, with limited access to tools, machines, space and material, which often creates situations where students in the same class are engaged in different tasks in the school workshop (Kilbrink et al., 2021). This was also the case when we visited the Sanitary, Heating and Property Maintenance Programme. The students in the Heating, Ventilation and Sanitation Engineering programme were engaged in various tasks during the period we visited the class. Scattered in two large workshop classrooms, and in different work booths, the students worked with elements such as assembling water heaters, toilet installations and boilers. The vocational teacher went from room to room to help students in their practical work. For video recording purposes, we used two cameras; one camera recorded two focus students (one at a time) and the other camera recorded the vocational teacher and his interaction with the students during the lessons.

When analysing the empirical data, first, the research group (the authors of this article) watched the films of the recorded lessons several times, both individually and together in the research group. After having categorised multiple clips in relation to longitudinal references in time, mainly focusing on a future doing, the analytic decisions that the authors made were presented, discussed and explored in several data sessions, until we agreed upon choosing two examples for a closer, in-depth analysis for this article. This is a common analytic procedure within interactional studies (Stevanovic \& Weiste, 2017).

In line with the CA approach that rests on a "methodological and epistemological naivety" (Schegloff, 1997, p. 185) we have aimed to ground this microanalysis from the participants' points of view. When identifying which actions and which learning content the participants themselves orient to as relevant at a specific point in the interaction, and to show this in a convincing way in the analysis, we have used the "proof procedure" method (Sacks et al., 1974) that has been developed within CA, which takes into account the viewpoints of the participants. This perspective involves the use of the participants' demonstrated interpretations of each other's actions as a resource in the analysis and as a means of enabling readers to judge the claims of the analyst, thus striving for the emic perspective mentioned above. In relation to the examples in this article, the evidence used to construct our analysis of what some 
bit of conduct is doing will be located in the data itself, and presented after each example below in a way that enables the reader to follow our analysis turn by turn (eg. Sidnell, 2013).

The chosen examples have been transcribed according to CA-conventions (eg. Hepburn \& Bolden, 2013) and analysed on a micro level using CAVTA, described above. Thereby, we made a close and detailed analysis of the interaction (mainly based on CA-tools) and the learning content made visible in the interaction (mainly based on tools from Variation Theory). Through the analysis, we can reach an understanding of which content is made relevant in the interaction and how it is oriented to here and now, but also in relation to the future (and the past). In this article, we have an explicit focus on the interaction that takes place in relation to the enacted object of learning, and we will therefore not discuss what the teacher aimed for or what the students actually learned. We follow the ethical principles stated by the Swedish research council (Vetenskapsrådet, 2017). For example, all participants (the teacher and the students) have been informed about the study and have given their written consent to participate, and the data reported from the study has been anonymised.

\section{$4 \quad$ Results and Analysis}

\subsection{The Importance of Following an Instruction}

In our first example, one of the students, John, has the task of assembling an underfloor heating system in a smaller stand, and at the beginning of one of the work sessions he turns to his teacher $(\mathrm{T})$ to ventilate what he is to do:

\section{Example 1A: the most important lore}

1. John: where should I start (.) with putting together rails?

2. T: either you start screwing together

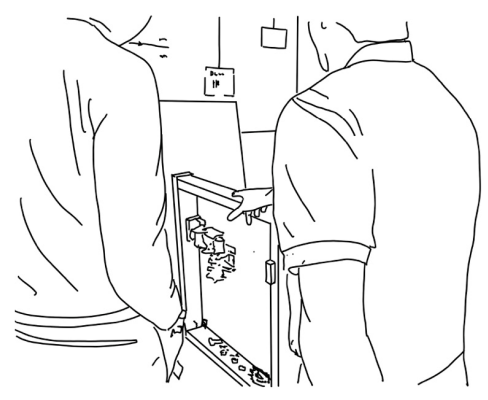



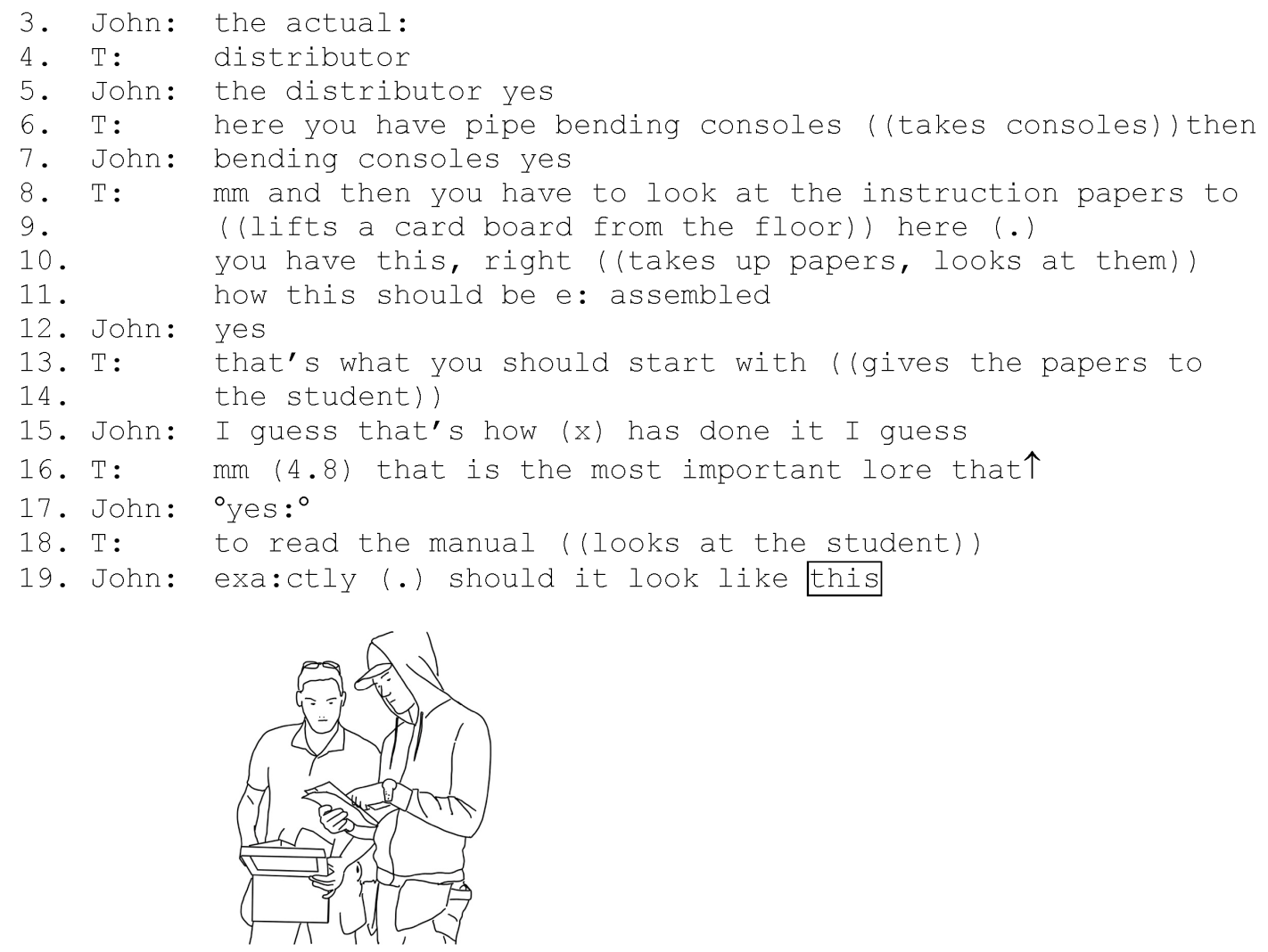

20. T: yes

21. John: although with two that is

22. T: although with two yes (.) because we only have two loops

23. John: yes

24. T: and then there you see that (llays the card board on the

25. floor, puts on glasses and points with a pen to the

26. paper)) 'there we have the pump you see (.) and that's

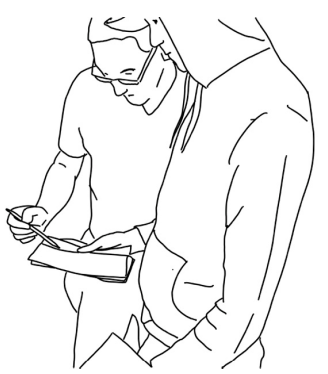




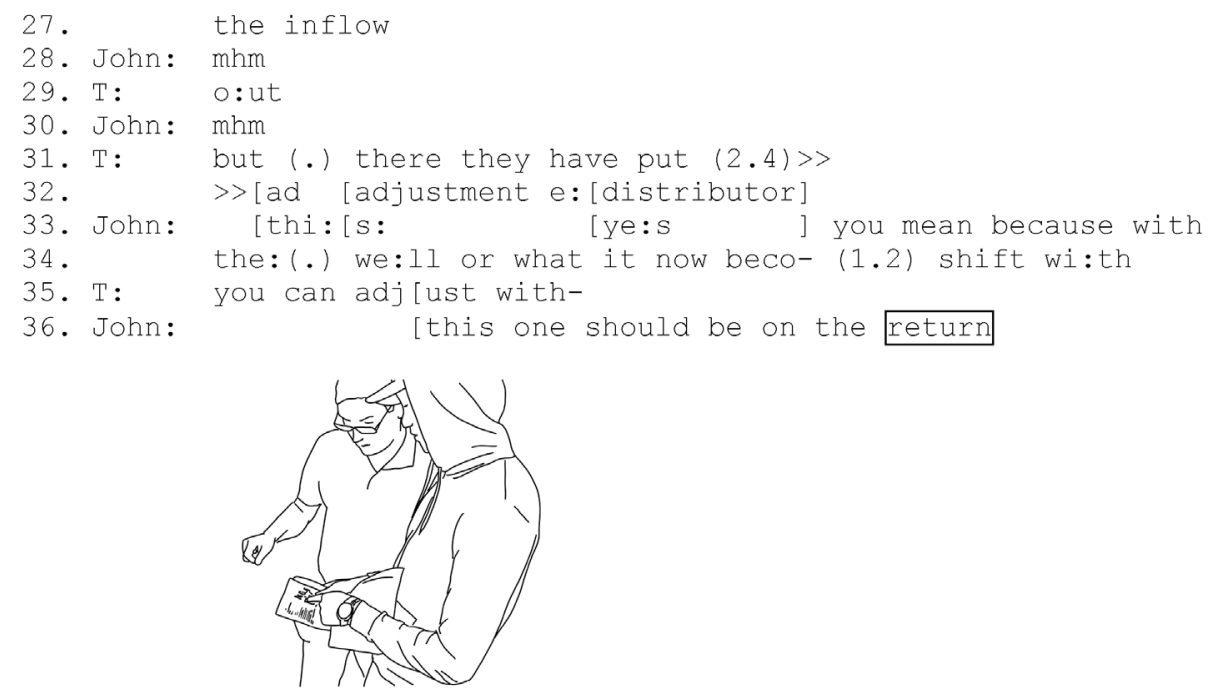

37. T: adjust the loops (.) "but here they have put in on the 38 . the inflow ${ }^{\circ}$

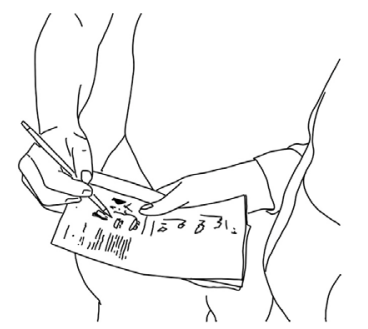

39. John: >yes I thought that $<$ because it should be on this

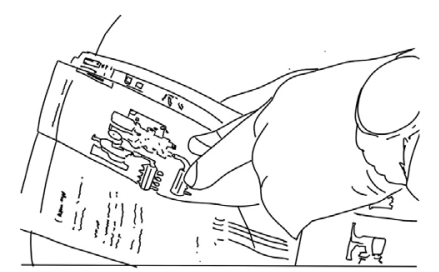

40. T: yes (.) but you will put it you do it as in the manual

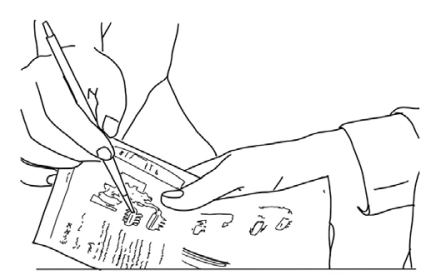

41. John: so now I will put e:

42. T: now you put it on the in[flow

43. John: [injustment (.) inflow? 

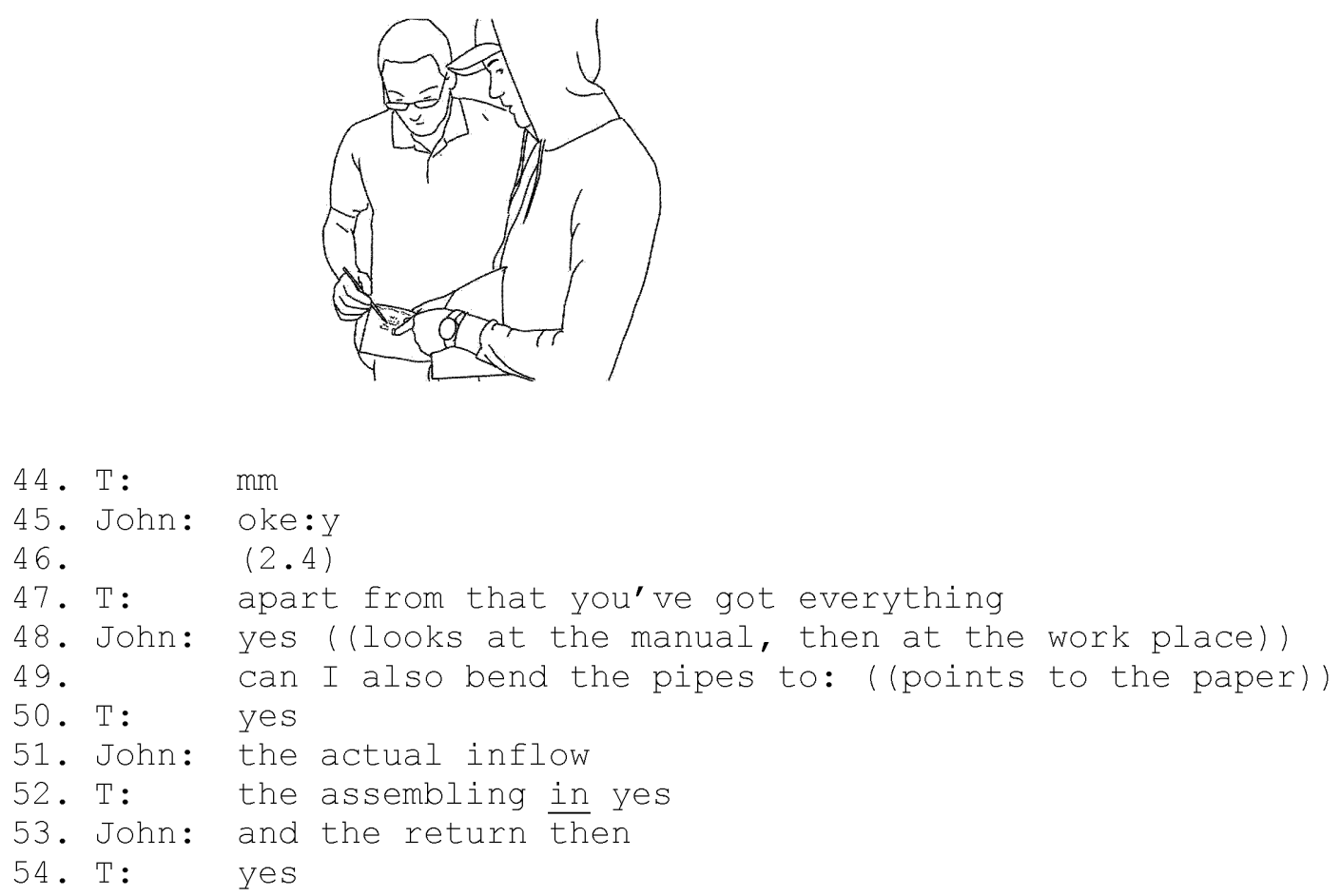

The example begins with the student initiating a movement towards the future doing by asking the teacher if he should start by assembling the rails. The teacher affirms and then a situation develops where the teacher together with the student discuss how the student should solve the task at hand, concerning the object of learning assembling an underfloor heating system. In the example, there are many clear explicit longitudinal orientations where the teacher and the student together talk about what should be done, how it should be done, and why it should be done in a specific way. In lines 2 and 4 , the teacher suggests that an alternative for the student would be to begin his work of screwing together "the distributor", whereupon he in lines 8-11 urges the student to look in the "instruction papers" which tell how the whole thing should be "assembled". This is what the student should "start with" (line 13), the teacher points out, at the same time as he hands over the instruction papers to the student.

In lines 16 and 18 the teacher then says that the "most important lore" is to "read the manual". The student then seeks confirmation from the teacher (which he gets on line 20) when asking if it should "look like this" at the same time as he points to the drawing he has just received from the teacher. The student then notices that the installation he should do himself differs from the one in the drawing, and the teacher then confirms that the one the student should work on "only" has "two loops". In this sequence, the work process emerges as an object of learning that in parallel follows the concrete doing of this particular task - laying underfloor heating. The teacher emphasises the reading of the manual as the central object of 
learning ("the most important lore") and that in it there is a process that must be followed in order to reach a certain goal. Already in lines 21-23, however, a variation between the number of loops that are on the manual and the number of loops that the student should use - i.e. a contrasting (as pattern of variation) of the number of loops as a critical aspect of assembling an underfloor heating system - emerges in the interaction between the teacher and student.

In lines 24-27, the teacher once again orients towards the drawing, and he also invites the student to do the same. This is followed by a longer sequence where the teacher and the student together, based on the manual, discuss how the continued work should be performed. Given the teacher's and student's dialogue, it appears that the placement of the adjustment distributor in the drawing differs from the placement it has on the material the student has to work with. Here, the teacher clarifies in line 40 that it is the manual that should be given priority, and that the distributor therefore should be put on the run. The object of learning that is in the foreground here is to follow the manual - but in relation to the content of the task in relation to laying underfloor heating, we can see a form of generalisation as pattern of variation, which concerns an interpretation where it is possible to conduct the task in another way (according to the student's suggestion, which is not clearly rejected by the teacher, but following the manual is given preferential interpretation). Here the student completes the teacher's turn by more precisely in line 43 conceptualising where the distributor is to be attached: On the "injustment (.) inflow". The slight rise in intonation at the end of the student's turn indicates some uncertainty, but the teacher's affirmative response leads to a situation where the student, together with the teacher in lines 44-54, also focuses on what to do next ("bend the pipes" to "the actual inflow" and "the return then".

After a longer break (4 seconds, not shown in the excerpt), the teacher points out that a large part of the actual "thinking job" (line 55), and what is "complicated" (line 56) in the work that the student is to perform is to "get it together" (line 58):

\section{Example 1B: the actual thinking job}

55. T: a large part is the actual thinking job (1.5) $\mathrm{mm}$ : what's

56. complicated is is this part

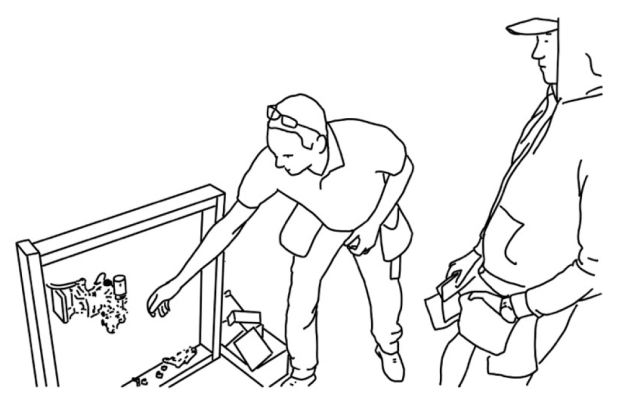




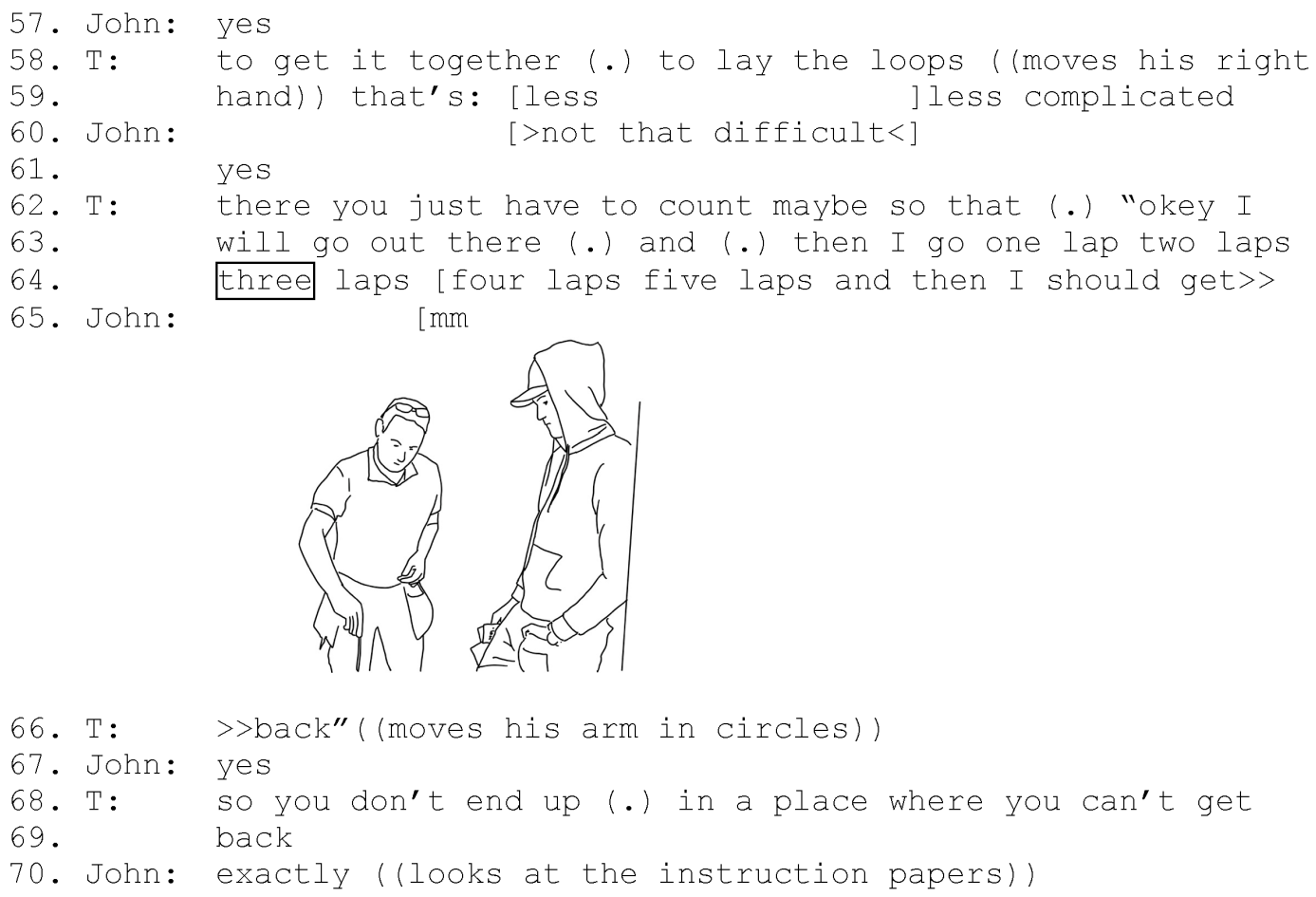

Exactly what "it" is that is complicated is not made explicit verbally, but given the teacher's physical orientation towards the module which the student is to connect, and the manual they both turn their attention to, it is probably about the work to be done based on the manual, and which they just talked about. Here, too, the work process and following the manual as the object of learning is given the foreground position in relation to the actual doing. What the teacher calls the "thinking job" appears as an expected critical aspect (Kilbrink \& Asplund, 2020), something that the teacher highlights as a potential difficulty in the upcoming work of laying the floor heating. Then the teacher orients towards - both verbally and physically - the work of laying the loops along the floor (lines 58). However, this work, unlike the other work, is a work that is "less complicated" (line 59) and the teacher receives support from the student who says that it is "not that difficult" (line 60). The teacher then makes another explicit longitudinal orientation when he introduces the student with the help of his embodied postures (Goodwin, 2000) to the upcoming work the student should do by publicly moving one arm back and forth in wide circular motions in the direction of the floor the student has to work on (lines 62-64 and 66). At the same time as he does that, he says that the only thing the student has to think about is to "count" the number of turns he should make loops, so that he does not "end up in a place" (line 68) where he "can't get back" (lines 68-69). When the teacher does this, he uses direct reported speech (Holt, 1996), and thus puts himself in the situation the student will end up in in the future. By counting the number of turns of the 
loops, at the same time as he reinforces the action by physically "simulating" the turns in front of him (and the student), he visualises the future doing for the student. Here, the ability to think ahead, to prepare and plan the work emerges as a critical aspect of the work process linked to the specific task of assembling an underfloor heating system.

The analysis of the interaction that takes place in example $1 \mathrm{~A}$ and $1 \mathrm{~B}$ clearly shows that it is the manual/instruction papers that should guide the student's future work. As soon as the student has shown the teacher that he wants to figure out how to handle the task he has in front of him, the teacher's and the student's attention is directed (on the teacher's initiative) towards the instruction papers. Here, and throughout the example, the teacher positions himself as the more knowledgeable (teacher) who knows what is important to consider when the work is to be performed, while the student, already through his initial question to the teacher, positions himself as the less knowledgeable who seeks support and guidance from the teacher (Melander, 2012). The work to be done with assembling an underfloor heating system is also not just something that the student is informed about merely by the teacher. Together and socially they work to establish a common understanding (Asplund \& Kilbrink, 2020) of what should be done, how it should be done and why it should be done in a specific way. When looking at this example as a coordinated interactional achievement, it is also apparent that the teacher and the student collaborate on both a verbal and bodily level. For example, in line 2 the teacher starts to explain what the student could start with, when the student smoothly fills in with a one-word utterance that fits the open syntactic structure. However, while indicating a word search (Goodwin \& Goodwin, 1986; Sacks, 1992), the teacher comes in to help the student complete his turn and integrates the student's contribution into his own utterance. In the student's next turn, both the repetition of the teacher's "distributor" and the definitive "yes", function to ratify that the teacher's completion was an acceptable offering for what the student was going to say.

There is also - throughout the example - a very clear longitudinal orientation towards the future action - and we can see that special attention is directed to some critical aspects that the student has to consider. The first is that the student "only" has two loops to work with and connect, unlike what the manual says. The second critical step concerns the location of the adjustment distributor, which differs from the manual. As soon as these two critical aspects have been made visible, by contrasting them as pattern of variation, the teacher emphasises that this is precisely the complicated work, as opposed to assembling an underfloor heating system. But, even in this work, there are some critical aspects; namely to lay out the "right" number of loops and to not end up in a situation where you "can’t get back" to the pump. 


\subsection{Movements Toward the Future Vocational Working Life}

In the next example, the student Liam has some difficulty unscrewing some pipe fittings. As soon as the teacher (Roger) has finished a short conversation with another student nearby, the student notes this and calls for the teacher's attention:

\section{Example 2: to have a long working life}

1. Liam: Roger how can I separate this pipe?

2. T: ((walks to the student)) take larger pliers

3. Liam: ((turns with the pair of pliers, struggles)) damn
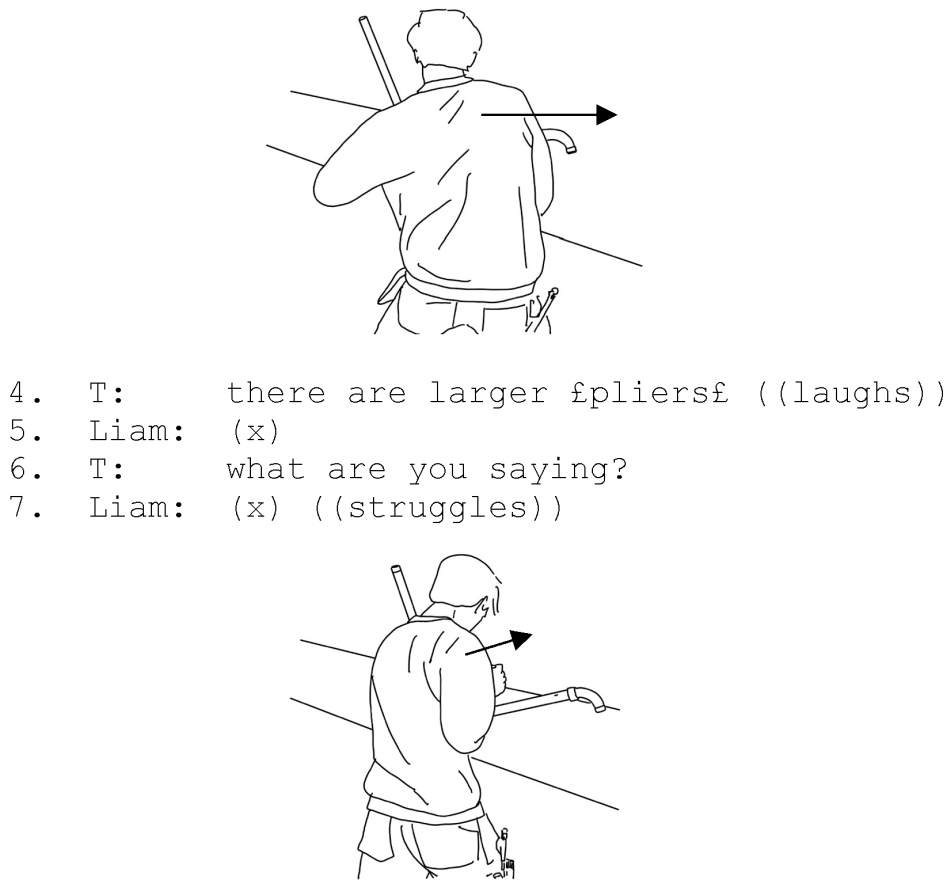

8. T: ye:s but e: : you are not getting much power are you

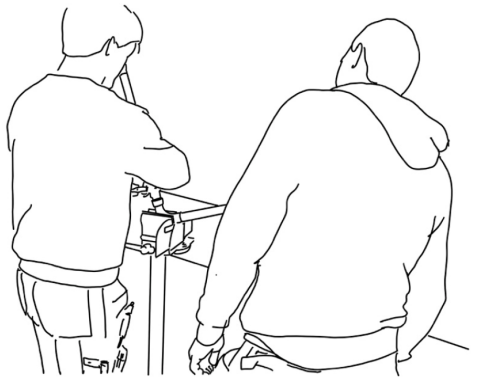


9. Liam: (x) I get all the [power from that one (lpoints to another 10. T: [all-

11. Liam: student, smiles))

12. T: we:ll I guess (.) but the thing is that (1.4) to be able

13. to have a long working life you should not have to use

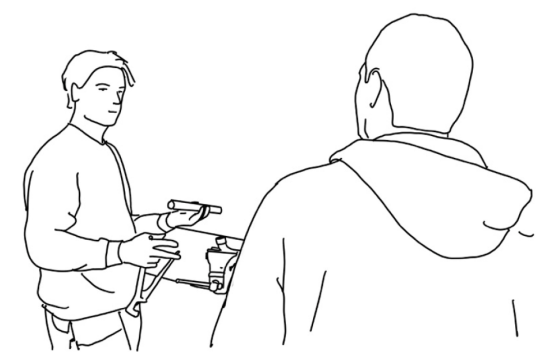

14. (1.6) all of your strength every day (.) the bigger tools

15. you've got (.) the less you have to use your body

16. Liam: well yes

17. T: and that is also important to keep in mind

18. Liam: oke:y

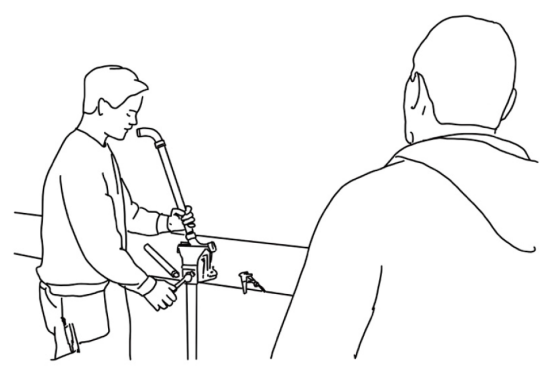

19. T: and then I wouldn't have set (.) the pipe like that

20. Liam: why then it doesn't move then

21. T: ((releases the pipe and screws it on again - in a new 22. position))
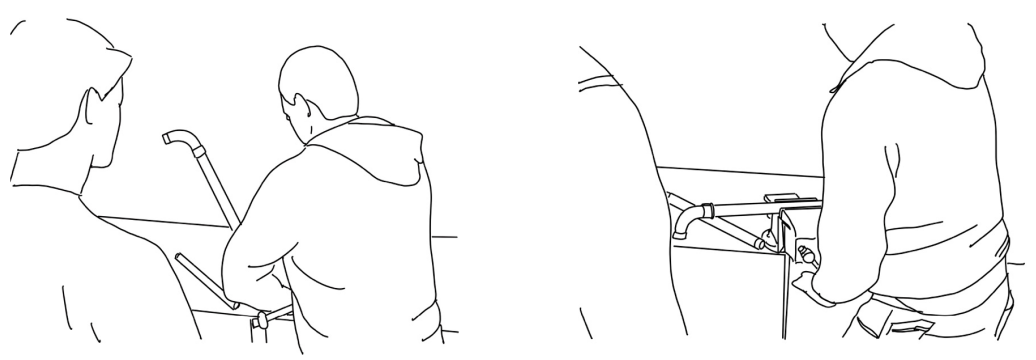
23. T: and then I had screwed it on that

24. Liam: mmwell that's true that's true

25. T: then you can imagine that instead of that you stand and

26. turn ((bends his body to the side)) (.) the pair of pliers

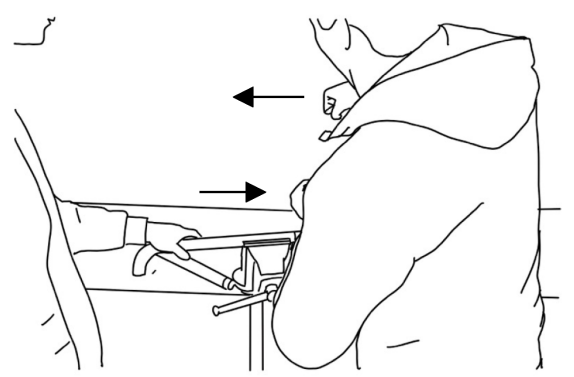

27. like this

28. Liam: yes

29. T: so now you should turn the part down ((screws the pair of

30. pliers on the pipe)) if you take a larger pair of pliers

31. and then you get the weight with you down so you can just

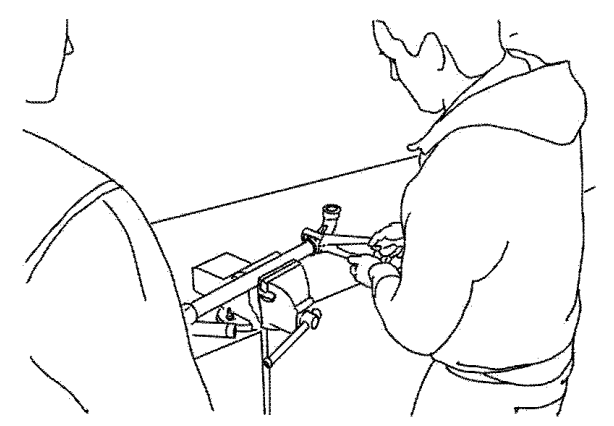

32. hang on like this

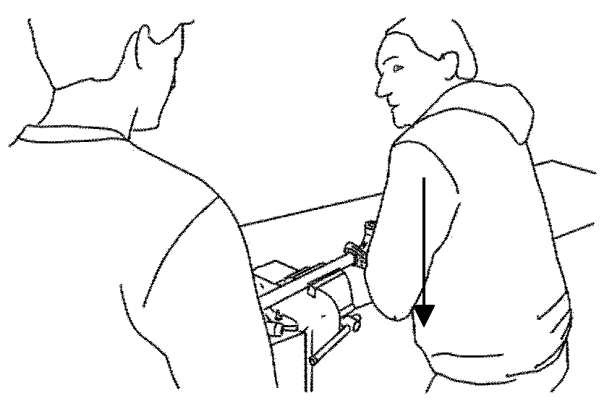

33. Liam: yes ((nods))

34. T: then [it is easy

35. Liam: [that's true (.) that's e:

36. T: ((leaves, turns around and points to the student)) but

37. take a larger (.) pair of pliers (.) that one yes 
In line 1 , the student initiates a longitudinal orientation towards the future doing by asking the teacher what he should do to separate the pipe parts from each other. The teacher then, after watching the student struggle with a pair of pliers, says that there are larger pliers (line 4, using a smiling voice and brief laugh particle (Jefferson, 1984)), and that the student's working position does not give him "much power" (line 8). The student then objects in a playful way, but then turns his gaze to the teacher who in line 12-15 develops a reasoning about the importance of finding work positions where you do not have to "use all of your strength (1.6) every day" (line 14). The teacher does this in relation to a longitudinal orientation towards the future professional life, and the argument put forward is that these are important aspects to keep in mind if you want to have a "long working life" (line 13). The teacher then, in lines 14-15, clarifies the whole thing by once again drawing attention to the tool and its size: "The bigger tools you've got, the less you have to use your body", and that this "is also important to keep in mind". Hence, in line 1 the student asks a concrete question that defines the object of learning that is in focus here and now (linked to the task at hand - to separate some pipe fittings), while the teacher then lifts up the question to an overall context and to a more overall object of learning, which is about using the right tools in a way that does not put strain on the body in order to have a long working life. In this overall context, the size of the tool then emerges as a critical aspect in the work of unscrewing the pipes, where the teacher uses contrasting as pattern of variation when comparing what the student does to what he instead should do. In this sequence, the size of the tool is linked to the power that the person using the tool can create. By applying more power from the tool, the user can put less strain on their body, which increases the opportunities for a longer working life in the industry.

In line 18, the student starts screwing the pipe into a new position in the vice, but given the teacher's response in line 19 to the student's action, there are other, and better ways of doing this. The student objects, asking why and claiming that it "doesn't move then". The teacher, however, continues and starts instructing the student how he could do this in a better and more ergonomic beneficial way. He does this by drawing attention to the future doing by first correcting the student's placement of the pipe in the vice (line 21-22) and then he says to the student that he had "screwed it on that" (line 23). The student then displays a changed understanding (line 24), agreeing with the teacher, whereupon the teacher both physically and verbally, first (in lines 25-26) shows how one can use the pair of pliers (which is presented as a less good way), and then he contrasts this way of doing with another way of using the pair of pliers, which the teacher highlights as more efficient. Hence, to use terminology from Variation Theory; contrast is used as a pattern of variation in relation to the critical aspect, that concerns the way of using the pair of pliers, of the object of learning how to use the right tools in a way that does not put too much strain on the body, in order to have a long working life. When doing this the teacher also uses his body to show how he can use the weight of his body in order to get more power into the pair of pliers, at the same time as he moves his head and gazes 
towards the student (see line 31-32). Following the teacher's instruction, the student and the teacher establish a common stance around the object of learning on how to use the right tools in a way that does not put too much strain on the body in order to have a long working life, whereupon the teacher leaves the student, but then turns around and reminds the student to use a larger pair of pliers (which he does). Thus, in relation to working ergonomically sustainable, the working position also emerges as a critical aspect (hence, something the student needs to evolve in his work), and is highlighted by the teacher using different semiotic resources simultaneously.

From the very beginning in the example, the student initiates a movement forward towards the future doing by asking a concrete question to the teacher. What then takes place is a situation where the teacher and the student together reason about how the work can proceed in the best way. The analysis shows how the student's actions initiate new movements forward in that the teacher steps in and clarifies and corrects the student's actions. Furthermore the teacher explains how to use the pair of pliers in a right way. There is also a clear longitudinal orientation towards what is to be done even outside the classroom context. The teacher thus broadens both the time and the space perspective when he draws the student's attention to the fact that the body is a work tool that should maintain a long working life, and that this is something one must consider, as well as an approach one must apply to the work already in the classroom.

\section{Discussion}

In this article, the focus has been on the teaching processes that are set into play when a vocational teacher and vocational students orient towards future-oriented longitudinally established learning content in vocational education when interacting in vocational plumbing workshop lessons. A prominent pattern in the analysed examples presented in this article is how the teaching is characterised by two parallel processes, which the teacher and the students have to deal with together and simultaneously. These parallel processes include different learning contents, where one process is about how a task that the students are engaged in should be solved in the here and now, and where the other process concerns aspects that are more explicitly linked to a future profession, but still in relation to the practical doing.

As mentioned above, previous research has highlighted different kinds of learning and knowledge within vocational education, where the vocational specific learning content is one part, and learning for life in general is another (Baartman \& de Bruijn, 2011; Eiríksdóttir \& Rosvall, 2019; Illeris, 2009; Kilbrink et al., 2018; Lindberg, 2003; Nylund \& Virolainen, 2019). However, in our study we can also see how different kinds of vocational learning and knowledge areas are simultaneously made relevant and oriented to in teaching situations in voca- 
tional plumbing education by focusing on explicit orientations to longitudinal established content in our analysis.

In all the examples in this article, we can see how the students direct their attention to the practical doing here and now, while the teacher in his teaching simultaneously and in parallel together with the students works to establish a common understanding of how the concrete work should be executed here and now, also highlights another dimension in the teaching in the form of an orientation towards a general object of learning. In the article's first example, we can see how the teacher highlights the work process itself and the art of following a manual in the work of assembling an underfloor heating system, where following a manual becomes the more general object of learning. In the second example in the article, the teacher raises issues related to ergonomics and thus draws the student's attention to the importance of working with the body in a gentle and sustainable way to enable a long working life as a general and overall object of learning, when the specific task is about unscrewing some pipe fittings.

In relation to our first research question that concerns how a common understanding of what is to be done and learned in vocational plumbing education is established in the interaction between a teacher and students, the analysis shows that the orientation towards the concrete practical doing here and now in the teaching situations are student-initiated actions, while it is the teacher who initiates movements towards a future oriented longitudinally established learning content. The analysis also shows that the teaching situations in the examples are situations that are created by the students and the teacher together and socially by e.g. positioning themselves as less knowledgeable (student position) and more knowledgeable (teacher position) (Melander, 2012) and by orienting towards an longitudinal explicit learning content (Sahlström, 2011; Sahlström et al., 2010). These two aspects - i.e. that the students and the teacher position themselves as teacher and students and orient themselves towards a specific learning content - are also the two necessary conditions for learning that Marton (2010) argues that teachers through their actions must contribute to creating in a teaching situation. According to Marton, one of the conditions is about the actual "learning pact" (Marton, 2010, p. 238, our translation) between the teacher and the students. To enable teaching and learning, the teacher must open up to supporting the students in the learning process, while the students in turn must show that they want to learn and want to receive the teacher's support. The second condition for learning is that the students experience the differences in content that are necessary for them to be able to discern the critical features of the object of learning (Marton, 2010). These two conditions for learning are also interdependent - they intersect and work together - and they require work and effort on the part of the teacher. Thus, the teacher must create conditions where he can interact with his students when supporting their learning trajectories (eg. de Saint-Georges \& Filliettaz, 2008; Filliettaz et al., 2015; Jakonen, 2018; Tapani \& Salonen, 2019), in relation to the specific learning content. Our analysis thus shows what happens when these two conditions for learning 
are created in the teaching situations we have analysed, and that they are the result of the teacher's and students' interactional accomplishments. As such, and in relation to our first research question, our findings are in line with those of Sakai et al. (2014) who emphasise the importance of technical knowledge of plumbing, as well as participants' interactional competences when establishing a shared recognition of spatiotemporally distant events and activities during the organisation and operation of a plumbing design in work settings.

On behalf of our second research question that concerns what content is made relevant in these processes, we can also see that when the teacher adds new objects of learning in the teaching situations, which in a sense is not something that is explicitly requested by the students, changed conditions are also created for the students' learning. In one respect, it is also conceivable here that the teachers' actions complicate the learning process for the students, as they are given more objects of learning that compete for the attention to relate to in the interaction with the teacher. One could argue that the teacher highlights more simultaneous aspects, which may make it difficult for students to experience the differences in content that are necessary for them to be able to discern the critical features of the content. However, with the support of Lo and Chik (2016) it is possible to argue that the teacher's strategies on the contrary can be strategies that can benefit students' learning in several respects, as the objects of learning and their critical aspects are handled and varied in relation to each other (internal horizons of fusion) but also in relation to a wider context (external horizons of fusion). What the teacher actually does is that he uses the students' commitment and publicly displayed focus as a didactic resource by putting what is to be done and learned here and now in a wider context. The specific learning content (object of learning) to which the students focus their attention (to unscrew pipes and to assemble an underfloor heating system) is incorporated simultaneously in a more overall and general context. As Lo and Chik (2016) argue, fusion in the external horizon may contribute to an understanding of how an object of learning is related to the wider context of the learning content in which it becomes a part. This movement may also lead to situations in which learning becomes connected with "real-world situation instead of isolated facts and knowledge" (Lo \& Chik, 2016, p. 307). Thus, making it possible for students to experience an object of learning as a part of a wider context of the learning content may be a fruitful strategy to enable students to experience the same object of learning in a more nuanced way, and to develop an understanding of the dynamic nature of the specific object of learning. In our study, this is also related to a practical doing and we can see how complex the interrelationship between different objects of learning is when oriented to in interaction. Altogether, and linking back to our second research question, this illuminates how the different layers of work-specific vocational learning are made visible in the interaction, and how they mutually contextualise each other in the here and now. 


\section{Conclusion}

In order to create favourable conditions for learning, it is important that teachers, together with students, establish a common understanding of what is to be learned, how it is to be learned and why it is to be learned in a specific way (Asplund \& Kilbrink, 2020; Hudson, 2007; Kilbrink \& Asplund, 2020). The content to be learned must also be defined, specified and communicated in order for students to be able to learn the content as well as possible (Marton, 2010). However, given the challenges students may encounter in practical doings in vocational work-shop sessions, vocational teachers may also consider the more general aspects that may discern as critical objects in the learning and teaching situation. Our analysis shows that this is not necessarily two different, separate, and countering processes that will complicate the students' learning trajectories. Rather, and with the support of Lo and Chik (2016), they can be used simultaneously and together, in order to open up for a more in-depth and nuanced learning of the specific object of learning that the students are supposed to learn in the teaching situation here and now. As such, our study emphasises the importance for vocational teachers to develop teaching strategies to navigate between contextualising the vocational learning content and making learning relevant for future vocational occupation and working life, and helping students in their problem solving and practical doings here and now.

In this study, teaching and learning has been approached as processes that include both the what-aspect and the how-aspect of teaching and learning. The use of CAVTA has enabled close and detailed analysis of these complex processes and made it possible to discern how, and in what ways, issues regarding form and content in the Sanitary, Heating and Property Maintenance Programme are closely interrelated and how they mutually contextualise each other in the analysed teaching and learning situations.

Nevertheless, we do not make any claims on how much or what the students actually learned, nor do we study what the teacher "really" intended with his teaching, limited as our study is to considering local interaction from an emic perspective (Duranti, 1997). However, it would be possible to study the whole teaching process by extending the approach taken in this study to teachers' and student's experiences of vocational knowing, and of the learning and teaching processes that takes place, in order to broaden the analysis of the local interaction in present. Another limitation with the study is that we are focusing on the teaching and learning processes that takes shape during lessons in one vocational program. Here, it would be fruitful to consider conducting more close studies of interaction in relation to teaching and learning a specific content on other VET programmes as well. This could contribute do a deeper knowledge and understanding of the complex processes that are set in play when vocational teachers and students interact in relation to a learning content. 


\section{Acknowledgement}

The research project is financed by the Swedish Research Council (ref no 2017-03552).

\section{References}

Andersson, P. (2019). Att utbilda nästa generation i yrket: En kunskapsöversikt om och för yrkeslärare [Educating the next generation in the profession: An overview of knowledge about and for vocational teachers]. Skolverket [the Swedish National Agency for Education].

Asplund, S-B., \& Kilbrink, N. (2018). Learning how (and how not) to weld: Vocational learning in technical vocational education. Scandinavian Journal of Educational Research, 62(1), 1-16. https:// doi.org/10.1080/00313831.2016.1188147

Asplund, S-B., \& Kilbrink, N. (2020). Lessons from the welding booth: Theories in practice in vocational education. Empirical Research in Vocational Education and Training, 12(1). https://doi. org/10.1186/s40461-020-0087-x

Baartman, L. K., \& de Bruijn, E. (2011). Integrating knowledge, skills and attitudes: Conceptualising learning processes towards vocational competence. Educational Research Review, 6(2), 125-134. https://doi.org/10.1016/j.edurev.2011.03.001

Baartman, L., Kilbrink, N., \& de Bruijn, E. (2018). VET students' integration of knowledge engaged with in school-based and workplace-based learning environments in the Netherlands. Journal of Education and Work, 31(2), 204-217. https://doi.org/10.1080/13639080.2018.1433821

Chan, S. (2017). The reciprocity of "imitative learning" through apprenticeship. Vocations and Learning, 10(3), 325-342. https://doi.org/10.1007/s12186-017-9175-x

de Saint-Georges, I., \& Filliettaz, L. (2008). Situated trajectories of learning in vocational training interactions. European Journal of Psychology of Education, 23(213). https://doi.org/10.1007/BF03172746

Duranti, A. (1997). Linguistic anthropology. Cambridge University Press.

Drew, P., \& Heritage, J. (2006). Editors' introduction. In P. Drew \& J. Heritage (Eds.), Conversation analysis (Vol. 1. pp. xxi-xxxvii). Sage.

Eiríksdóttir, E., \& Rosvall, P. Å. (2019). VET teachers' interpretations of individualisation and teaching of skills and social order in two Nordic countries. European Educational Research Journal, 18(3), 355-375. https://doi.org/10.1177/1474904119830022

Filliettaz, L., Durand, I., \& Trébert, D. (2015). Learning through verbal interactions in the workplace: The role and place of guidance in vocational education and training. In L. Filliettaz \& S. Billett (Eds.), Francophone perspectives of learning through work. Professional and practice-based learning (Vol 12, pp. 279-301). Springer.

Goodwin, C. (2000). Action and embodiment within situated human interaction. Journal of Pragmatics, 32(10), 1489-1522. https://doi.org/10.1016/S0378-2166(99)00096-X

Goodwin, C. (2006). Human sociality as mutual orientation in a rich interactive environment: Multimodal utterances and pointing in aphasia. In N. J. Enfield \& S. C. Levinson (Eds.), Roots of human sociality: Culture, cognition and interaction (pp.97-125). Berg.

Goodwin, M. H., \& Goodwin, C. (1986). Gesture and coparticipation in the activity of searching for a word. Semiotica, 62(1-2), 51-75. https://doi.org/10.1515/semi.1986.62.1-2.51 
Gåfvels, C. (2016). Vision and embodied knowing: The making of floral design. Vocations and Learning, 9(2), 133-149. https://doi.org/10.1007/s12186-015-9143-2

Hepburn, A., \& Bolden, G. B. (2013). The conversation analytic approach to transcription. In J. Sidnell \& T. Stivers (Eds.), The handbook of conversation analysis. Wiley Blackwell.

Holt, E. (1996). Reporting on talk: The use of direct reported speech in conversation. Research on Language and Social Interaction, 29(3), 219-245. https://doi.org/10.1207/s15327973rlsi2903_2

Hudson, B. (2007). Comparing different traditions of teaching and learning: What can we learn about teaching and learning? European Educational Research Journal, 6(2), 135-146. https://doi. org/10.2304/eerj.2007.6.2.135

Illeris, K. (2009). Transfer of learning in the learning society: How can the barriers between different learning spaces be surmounted, and how can the gap between learning inside and outside schools be bridged? International Journal of Lifelong Education, 28(2), 137-148. https://doi. org/10.1080/02601370902756986

Jakonen, T. (2018). Retrospective orientation to learning activities and achievements as a resource in classroom interaction. The Modern Language Journal, 102(4), 758-774. https://doi.org/10.1111/ $\bmod .12513$

Jefferson, G. (1984). On the organization of laughter in talk about troubles. In J. M. Atkinson \& J. Heritage (Eds.), Structures of social action: Studies in conversation analysis (pp.347-369). Cambridge University Press.

Kilbrink, N., \& Asplund, S.-B. (2018). "This angle that we talked about": Learning how to weld in interaction. International Journal of Technology and Design Education, 30(1), 83-100. https://doi. org/10.1007/s10798-018-9490-Z

Kilbrink, N., Asplund, S.-B., \& Asghari, H. (2021). Introducing the object of learning in interaction: Vocational teaching and learning in a plumbing workshop session. Journal of Vocational Education \& Training. https://doi.org/10.1080/13636820.2020.1850512

Kilbrink, N., Bjurulf, V., Olin-Scheller, C., \& Tengberg, M. (2014). Experiences of educational content in Swedish technical vocational education: Examples from the energy and industry programmes. International Journal of Training Research, 12(2), 122-131. https://doi.org/10.1080/14480220.201 4.11082035

Kilbrink, N., Bjurulf, V., Baartman, L., \& de Bruijn, E. (2018). Transfer of learning in Swedish technical vocational education: Student experiences in the energy and industry programmes. Journal of Vocational Education \& Training, 70(3), 455-475. https://doi.org/10.1080/13636820.2018.1437064

Khaled, A., Gulikers, J., Biemans, H., \& Mulder, M. (2016). Occurrences and quality of teacher and student strategies for self-regulated learning in hands-on simulations. Studies in Continuing Education, 38(1), 101-121. https://doi.org/10.1080/0158037X.2015.1040751

Lave, J. (1993). The practice of learning. In S. Chaiklin \& J. Lave (Eds.), Understanding practice: Perspectives on activity and context (pp. 3-34). Cambridge University Press.

Lindberg, V. (2003). Learning practices in vocational education. Scandinavian Journal of Educational Research, 47(2), 157-179. https://doi.org/10.1080/00313830308611

Lo, M. L. (2012). Variation theory and the improvement of teaching and learning. Acta universitatis Gothoburgensis. https://gupea.ub.gu.se/bitstream/2077/29645/5/gupea_2077_29645_5.pdf

Lo, M. L., \& Chik, P. P. M. (2016). Two horizons of fusion. Scandinavian Journal of Educational Research, 60(3), 296-308. https://doi.org/10.1080/00313831.2015.1119730 
Lucas, B., Spencer, E., \& Claxton, G. (2012). How to teach vocational education: A theory of vocational pedagogy. The City and Guilds of London Institute. https://www.worldskillsuk.org/media/1835/ how-to-teach-vocational-education.pdf

Marton, F. (2010). Samtalsanalys och pedagogik [Conversation analysis and pedagogy]. In H. Melander \& F. Sahlström (Eds.), Lärande i interaction [Learning in interaction] (pp. 216-242). Liber.

Marton, F. (2015). Necessary conditions of learning. Routledge.

Marton, F., \& Tsui, A. B. M. (Eds.) (2004) Classroom discourse and the space of learning. Erlbaum.

Melander, H. (2012). Knowing how to play the game of jump rope: Participation and stancetaking in a material environment. Journal of Pragmatics, 44(11), 1434-1456. https://doi.org/10.1016/j.pragma.2012.06.018

Melander, H., \& Sahlström, F. (2010). Lärande i interaktion [Learning in interaction]. Liber.

Nore, H. (2015). Re-contextualizing vocational didactics in Norwegian vocational education and training. International journal for research in vocational education and training, 2(3), 182-194. https:// doi.org/10.13152/IJRVET.2.3.4

Nylund, M., \& Virolainen, M. (2019). Balancing "flexibility" and "employability": The changing role of general studies in the Finnish and Swedish VET curricula of the 1990s and 2010s. European Educational Research Journal, 18(3), 314-334. https://doi.org/10.1177/1474904119830508

Pang, M. F., \& Ki, W. W. (2016). Revisiting the idea of "critical aspects". Scandinavian Journal of Educational Research, 60(3), 323-336. https://doi.org/10.1080/00313831.2015.1119724

Sacks, H. (1992). Lectures on conversation (Volume 1). Blackwell.

Sacks, H., Schegloff, E.A., \& Jefferson, G. (1974). A simplest systematics for the organization of turn-taking in conversation. Language, 50(4), 696-735.

Sahlström, F. (2011). Learning as social action. In J. K. Hall, J. Hellermann \& S. P. Doehler (Eds.), L2 interactional competence and development (pp. 45-65). Multilingual Matters.

Sahlström, F., Hummelstedt, I., Forsman, L., Pörn, M., \& Slotte-Lüttge, A. (2010). Samma innehåll olika sammanhang: Mikro-longitudinellt lärande i sjuåringars vardag [Same content, different contexts: Micro-longitudinal learning in seven-year-olds' everyday lives]. In C. Lindholm \& J. Lindström (Eds.), Språk och interaktion 2 [Language and interaction 2] (pp. 1-22). University of Helsinki.

Sakai, S., Korenaga, R., Mizukawa, Y., \& Igarashi, M. (2014). Envisioning the plan in interaction: Configuring pipes during a plumbers' meeting. In M. Nevile, P. Haddington, T. Heinemann \& M. Rauniomaa (Eds.), Interacting with objects: Language, materiality, and social activity (pp. 339-356). John Benjamins Publishing Company.

Schaap, H., Baartman, L. K. J., \& de Bruijn, E. (2012). Students' learning processes during schoolbased learning and workplace learning in vocational education: A review. Vocations and Learning, 5(2), 99-117. https://doi.org/10.1007/s12186-011-9069-2

Schaap, H., van der Schaaf, M., \& de Bruijn, E. (2017). Interactions in vocational education: Negotiation of meaning of students and teaching strategies. Studies in Continuing Education, 39(1), 52-70. https://doi.org/10.1080/0158037X.2016.1234451

Schegloff, E.A. (1997). Whose text? Whose context? Discourse \& Society, 8(2), 165-187. https://doi.or g/10.1177\%2F0957926597008002002

Schegloff, E. A. (2007). Sequence organization in interaction. A primer in conversation analysis 1. Cambridge University Press.

Sidnell, J. (2013). Basic conversation analytic methods. In J. Sidnell \& T. Stivers (Eds.), Conversation analysis (pp. 77-99). Wiley Blackwell. 
Stevanovic, T. M., \& Weiste, E. H. (2017). Conversation-analytic data session as a pedagogical institution. Learning, Culture and Social Interaction, 15, 1-17. https://doi.org/10.1016/j.lcsi.2017.06.001

Säljö, R. (2005). Lärande och kulturella redskap. Om lärprocesser och det kollektiva minnet [Learning and cultural tools: About learning processes and the collective memory]. Norstedts Akademiska Förlag.

Tapani, A., \& Salonen, A. O. (2019). Identifying teachers' competencies in Finnish vocational education. International Journal for Research in Vocational Education and Training, 6(3), 243-260. https:// doi.org/10.13152/IJRVET.6.3.3

Tuomi-Gröhn, T., \& Engeström, Y. (2003). Between school and work: New perspectives on transfer and boundary-crossing. Pergamon.

Vetenskapsrådet. (2017). God forskningssed [Good research practice]. Vetenskapsrådet [Swedish Research Council].

Öhman, A. (2018). Twist and shape: Feedback practices within creative subject content of hairdressing education. Vocations and Learning, 11(3), 425-448. https://doi.org/10.1007/s12186-017-9196-5

Öhman, A., \& Tanner, M. (2017). Creating space for students' concerns: Embodied feedback practices in hairdressing education. Learning, Culture and Social Interaction, 14, 79-93. https://doi. org/10.1016/j.lcsi.2017.04.005

\section{Biographical Notes}

Dr Stig-Börje Asplund is Associate Professor at the Department of Educational Studies at Karlstad University in Sweden. His research interests include classroom interaction, processes of identity construction, and literacy practices, with a special focus on vocational education and on boys' and men's relationship to reading.

Dr Nina Kilbrink is Associate Professor at the Department of Educational Studies at Karlstad University in Sweden. Her research interests concern for example vocational education, ICT in education, professional learning, and technical education, with a specific focus on teaching and learning and the relationship between theory and practice.

Dr Hamid Asghari holds a PhD in Educational Work at the Department of Educational Studies at Karlstad University in Sweden. His research interests concern vocational education, with a special interest in vocational teaching and learning. 